Print ISSN: 2233-4165 / Online ISSN: 2233-5382

doi:http://dx.doi.org/10.13106/ijidb.2018.vol9.no7.61.

\title{
The Intention of Repurchase on e-Service Quality by Online Travel Agency Site
}

\section{온라인 여행사 사이트 e-서비스품질이 지각된 가치, 만족도, 재구매의도에 미치는 영향**}

\author{
Ling-Xiao $\operatorname{Niu}(\text { 우릉소 })^{* *}$, Jong-Ho Lee(이종호 ${ }^{* * *}$
}

Received: June 19, 2018. Revised: July 4, 2018. Accepted: July 15, 2018.

\section{Abstract}

Purpose - The purpose of this research is reflected on the rapid development of online tourism industries. The study was to establish the strategy for Korean tourism enterprises to develop tourist commodities suitable for Chinese tourists and attract them to visit Korea by the empirical analysis of the relation between repurchase intention of tourists and its premise variables (e-service quality, perceived value and satisfaction).

Research design, data, and methodology - This research carried out a questionnaire survey on Chinese tourists who visited Korea with experience of using the online travel agency web sites. A total 398 answers were recovered, 41 of them were excluded due to the dishonest answers and 357 of them were finally analyzed. The data was analyzed with IBM SPSS AMOS 22.0.

Results - The research results show that in the online travel agency web site e-service quality, convenience, interactivity, information validity, credibility had a positive impacts on perceived value and satisfaction. The perceived value of online travel agency website users has positive impart on satisfaction and repurchase intention. Satisfaction of online travel agency web site users have positive impacts on repurchase intention. But safety has no impact on perceived value while positive impacts on satisfaction was affected.

Conclusions - First, in the online travel agency web site e-service quality, safety has no impact on perceived value while it was shown to have positive impacts on satisfaction because the users of online travel agency web sites believe that the protection of personal information, the defense of cracker and the safeguard of payment security are the basic premises of website operation. Although safety does not have impacts on perceived value, users benefits will suffer damage when hacker intrusion and other accidents occur so that online travel agency web sites should not ignore the security concerns. Second, credibility is a major concern for online travel agency web site users. At this time, it is necessary for the web site to establish a system to display both the commodity information and the using experience published on the user's SNS, thus improving the credibility of the website information.

Keywords: Online Travel Agency Websites, E-Service Quality, Repurchase Intention.

JEL Classifications: M10, M19, M50.

* This is an abbreviation of Master Thesis by Niu.

** First Author, Master. Candidate of Electronic Commerce, Dept. of Kongju National University, majoring in Electronic Commerce, China. E-mail: nlx2442@gmail.com

*** Corresponding Author, Professor, Dept. of Kongju National University, majoring in Electronic Commerce, Korea. Tel: +82-41-850-8257, E-mail: leejh@kongju.ac.kr

\section{1. 서론}

중국 국가통계국의 데이터에 따르면, 2016년 중국의 국내 총생산(GDP)은 744,127 억 위안으로 1978년 이후 연평균 약 $15 \%$ 로 성장하였고, 규모면에서도 약 188 배 증가한 놀라운 성 과를 달성하였다(Song \& Lee, 2018). 최근 몇 년간 중국에서 는 관광소비가 국민 생활소비 분야의 중요한 구성 부분의 하 나가 되었다. 특히 해외여행은 일부 중고소득 가구들의 휴가 기간 사용하는 주요 레저 활동 방식이 되었다. 2017년 중국인 출국 연인원은 1.3 억 명이며, 전년 대비 $6.6 \%$ 성장하였다. 중 
국의 소비규모가 커짐에 따라 2020년 중국 해외 관광 소비 시 장 규모가 2,000억 달러 넘어설 것이라는 분석이 나왔다. 과거 중국 소비자들의 해외 관광 활동은 일반적으로 전통 여행사에 의존하였다. 그러나 점차 관광 소비 규모가 늘고, 관광객들의 요구사항이 다양해지면서 여행객들의 기대와 관광객의 개별수 요를 만족시키기가 어려워졌다.

중국 인터넷 사용자 규모는 2017년 12월에 7.2억 명을 넘 어섰다. 인터넷 보급률은 $55.8 \%$ 로, 2016년 말 대비 $2.6 \%$ 증 가하였다. 인터넷의 보급에 따라 전자상거래도 빠르게 발전하 고 있다. 2003년부터 최근까지 중국 온라인 여행 예약 시장의 성장률은 지속적으로 성장하고 있다.

웹사이트를 통한 여행상품의 판매로 고객은 전통 여행사를 통하는 방법보다 정보를 쉽고 빠르게 획득할 수 있으며 다양 한 여행상품을 선택할 수 있어서 편리하다. 인터넷의 발전에 따라 중국 관광객들 중 많은 젊은이들이 여행 웹사이트나 스 마트 폰을 통해 여행상품을 결정한다.

소비자에게 있어 친숙한 브랜드는 다른 브랜드에 비해 비교 적 믿을만하고 높은 만족도를 가지고 있으므로 여행시장에서 우위를 점할 수 있다. 다른 기업과의 경쟁우위를 선점하기 위 하여 소비자들에게 쉽게 인지시킬 수 있는 마케팅방법을 세우 는 전략에 대한 연구가 필요하다.

소비자의 재 구매를 적극적으로 유도하기 위해서는 소비자 들에 대한 이해 및 현재 온라인 여행사의 특성에 대한 세밀한 연구가 요구된다. 즉 실제 인터넷상의 여행사를 통해서 여행을 결정하기 위한 소비자의 만족도, 지각된 가치에 영향을 미치는 주요 요인들에 대한 연구가 필요하다.

한국 관광시장은 새로운 환경에 직면하면서, 한국 온라인 여행 기업이 어떻게 새로운 기회를 잡고 중국 온라인 여행기 업의 이점과 문제점을 종합하여 중국 관광객들에게 적합한 관 광 상품을 개발할 수 있을 것인가를 위한 연구가 필요하다고 할 수 있겠다.

본 연구는 온라인 여행업의 급속한 성장에 따른 관광객 재 구매의도와 그 선행변수로 e-서비스품질, 지각된 가치, 만족도 를 설정하고 이들 간의 관계를 실증 분석함으로써 이를 통해 한국 여행 기업이 중국 관광객에게 적합한 상품을 개발하며 한국관광을 유도하기 위한 전략을 제시하고자 하는 목적이 있 다. 모든 서비스 기업이 주목하는 핵심은 서비스의 품질이다. 품질을 높이면 서비스는 고객만족도를 향상시키고 고객의 구매 의도를 유도하여 기업에게 좋은 평가를 가져다주며 거대한 수 익을 창출할 수 있다. 따라서 본 연구의 목적은 다음과 같다.

첫째, 선행연구를 바탕으로 온라인 여행기업의 e-서비스품 질의 구성 차원을 다시 확인하고, e-서비스품질에 대한, 고객 지각된 가치와 만족도의 개념을 명확히 제시한다.

둘째, 온라인 여행사 사이트의 e-서비스품질과 이용자의 지 각된 가치, 만족도, 재 구매의도 간의 관계를 실증분석을 통해 검증한다.

셋째, 실증분석에서 나타난 결과를 통해 중국 관광객들의 방한 관광 상품에 대한 요구사항을 알아보고, 특히 한국의 여 행사들이 온라인 여행사 사이트를 통해 중국 관광객을 유치하 기 위한 방안과 전략을 제시한다.

본 연구의 목적을 달성하기 위해서 우선 이론적 연구방법으 로 여행기업의 e-서비스품질, 고객의 지각된 가치, 만족도, 재 구매의도와 관련된 문헌을 폭넓게 고찰해 봄으로써 기존의 연 구관점과 방향 및 문제점들을 밝혀내고자 하였다. 또한 온라인 여행기업의 e-서비스품질 구성요인을 다시 분석했으며, 온라인
여행기업의 e-서비스품질에 대한 고객만족도와 지각된 가치의 관계 및 재구매의도의 관계에 대한 선행연구를 기술하였다. 이 를 바탕으로 연구 모형을 정립하며 연구가설을 설정하였다. 이 러한 연구가설의 타당성과 신뢰성에 대한 실증적인 분석을 위 해 온라인 여행사의 이용 경험이 있는 방한 중국인 관광객을 대상으로 설문조사를 실시하였다. 설문조사를 통해 수집된 데 이터는 SPSS 22.0을 이용하여 분석하고 결과를 정리하였다.

\section{2. 이론적 배경}

\section{1. 온라인 여행사 사이트에 관한 이론적 고찰}

\subsection{1. 온라인 여행사의 개념}

여행사(travel agency)는 여행 주최자가 대중에게 가능한 여행, 숙박 및 관련 서비스에 대한 자료를 제공하고 판매하는 기관이 다. 교통편을 조직하고, 다른 숙박 시설을 예약하고, 여행 및 거 주를 준비하기 위해 모든 부가 서비스를 제공한다. 여행사는 이 익 창출을 목적으로 관광 사업에 종사하는 회사를 지칭한다.

현재 글로벌 전자상거래에서 관광 전자상거래는 점유율의 $1 / 5$ 을 차지하여 글로벌 전자상거래의 첫 번째 산업이 되었다. 이러한 상황에 직면하여 중국 여행사들은 전환점을 맞이하고 있다. 2000년 중국의 전자상거래는 관광 전자상거래가 선두 자리를 차지하면서 상위 10 대 산업에서 선정되었다.

Online Travel Agency(OTA)는 온라인 여행사를 일컫는 용 어로 중국어 정식 명칭은 “线上旅行社”라고 하며, 여행 전자상 거래 업계의 전문 용어이다. 여행 상품이나 서비스를 예약한 소비자가 인터넷을 통해 서비스 제공 업체를 이용하고 온라인 또는 오프라인으로 지불하는 것, 즉 개별 여행사가 인터넷을 사용하여 제품 마케팅이나 제품 판매를 수행하는 것을 말한다.

\subsection{2. 여행사 사이트의 정의}

여행사 웹사이트에 대한 개념을 살펴보면, 여행사 사이트는 사이버 공간에서 네티즌들에게 원하는 여행상품 및 정보를 제 공하는 사이트라고 정의할 수 있다.

또한 이용자들을 대상으로 여행에 필요한 정보와 여행상품, 기타 안내 사항 등을 콘텐츠로 구축하여 화면으로 제시함은 물론 여행상품 판매가 가상공간에서 이루어지고 있는 인터넷 상의 사이트를 여행사 웹사이트로 정의하였다.

\subsection{3. 온라인 여행사의 이점}

관광 산업은 관광객의 요구에 따라 지속적으로 변화한다. 과거의 전통적인 여행사는 소비자의 변화하는 요구를 충족시 키기가 매우 어려웠다. 여행사는 업무를 운영하여 항상 높은 임대료를 지불해야 한다. 또한 운영비(수도, 전기, 부동산 등 포함)를 많이 지출해야 한다. 모든 비용은 결국 관광객들로부 터 이익을 얻는 것이어야 한다. 전통적인 여행사는 많은 어려 움에도 불구하고 경쟁력과 영향력을 높이기 위해 다수의 종사 자들이 사업을 인터넷으로 옮겼다. 이러한 변화는 잠재 고객과 영향력을 효과적으로 확장할 수 있기 때문에 비용의 절감이 가능하고, 좀 더 저렴한 가격으로 동일한 품질의 제품이나 서 비스 제공을 통해 결국 소비자에게 혜택을 줄 수 있다. 


\subsection{4. 중국 온라인 여행업 시장 현황}

중국의 온라인 여행업은 주로 온라인 교통, 온라인 숙박, 온 라인 휴가 여행의 세 가지 시장을 포함하며, 최근 주요 시장 현황은 다음과 같다.

(1) 2017 년 중국의 온라인 여행 시장 거래량은 $7,195.4$ 억 위 안으로 $26.5 \%$ 의 성장률을 보였으며, 성장 추세는 비교적 안정 적이다.

(2) 2017년 중국의 온라인 여행 시장의 거래 구조를 볼 때 거래의 절반이 교통을 차지하고 있으며, 휴가 여행의 비율이 점차 증가하고 숙박은 비교적 안정적으로 유지되는 것으로 나 타났다.

(3) 2017년 온라인 여행 업계에서 Ctrip.com과 Qunar.com은 여전히 최고의 시장 점유율을 차지했다.

(4) 스마트폰의 보급에 따라 점점 더 많은 사용자가 PC보다 모바일 거래를 선호하였으며, 여행사이트 사용자에 대한 분석 도 마찬가지로 나타났다. 2017년 10월 모바일 방문 횟수는 총 방문량의 $77 \%$ 를 차지했다.

(5) 국민의 소득이 증가함에 따라 관광 소비는 다각화 단계 에 접어들었다. 여행은 주로 비즈니스 여행과 휴가 여행으로 구분되었으며, 남성과 여성 간에도 큰 차이는 없었다. 주로 1 등급 도시와 2등급 도시의 $26 \sim 45$ 세 사이의 고소득 소비자들 의 이용이 늘고 있다.

\section{2. 서비스품질에 관한 이론적 고찰}

\subsection{1. 서비스품질의 개념}

Parasuraman et al.(1988)은 서비스 품질을 서비스의 우수 성과 관련된 소비자들의 전반적인 판단 및 태도라고 정의하였 다. Lewis and Booms(1983)은 서비스 품질은 지각된 서비스 가 고객들의 기대와 얼마나 일치하는가의 정도라고 정의하고 고객의 기대에 일치되도록 서비스를 제공하는 것을 의미한다 고 하였다. Gronroos(1984)는 서비스 품질이란 고객들의 인지 된 서비스와 기대된 서비스의 비교의 결과라고 정의하였으며, 고객의 기대, 품질, 이미지 등 변수와 함수관계에 있다고 하였 다.

Santos(2003)은 e-서비스 품질을 웹사이트와 고객과의 상호 작용을 포함하는 광범위적인 개념으로 웹사이트에서 효율적이 고 효과적으로 쇼핑 및 배송을 촉진하는 정도로 정의하였다.

서비스품질은 온라인 기업의 생존에 중요하다. 이제 e-서비 스 품질의 도입은 선택할 사항이 아닌 기업의 필수 사항이다. 이에 따라 최근에 인터넷상의 서비스 품질에 관한 많은 연구 가 이루어져 왔다(Zeithaml et al., 2000; Santos, 2003; Fassnacht \& Koese, 2006).

\subsection{2. 서비스품질의 구성요인}

서비스 품질의 구성요인들은 서비스 품질에 영향을 준다. Carman(1990)은 서비스 품질 구성요인을 신뢰성, 접근성, 예 절, 신용도, 안정성, 고객의 이해 등 10 가지로 제시하였다.
<Table 1> 10 factors customers use to evaluate service quality

\begin{tabular}{|c|l|}
\hline Factors & \multicolumn{1}{|c|}{ Definition } \\
\hline Tangibility & The shape clues to realize service evaluation \\
\hline Credibility & $\begin{array}{l}\text { The ability to execute the agreed service } \\
\text { correctly }\end{array}$ \\
\hline Response & $\begin{array}{l}\text { Take delight to help customers and provide } \\
\text { quick service }\end{array}$ \\
\hline Ability & $\begin{array}{l}\text { The necessary technology and knowledge to } \\
\text { execute service }\end{array}$ \\
\hline Etiquette & $\begin{array}{l}\text { Employee's kind, caring and respect to } \\
\text { customers }\end{array}$ \\
\hline Credit line & The sincerity and integrity of service provider \\
\hline Safety & Avoiding danger and suspicions \\
\hline Be accessible & Be accessible and the comfort level of contact \\
\hline Communication & $\begin{array}{l}\text { Listening to customers' opinions and informing } \\
\text { customer with simple words }\end{array}$ \\
\hline $\begin{array}{c}\text { Customer } \\
\text { understanding }\end{array}$ & $\begin{array}{l}\text { Trying best to inform customers and satisfying } \\
\text { their demands }\end{array}$ \\
\hline
\end{tabular}

\section{3. 온라인 여행사 e-서비스품질의 구성요인}

\subsection{1. 편리성에 과한 연구}

연구자들은 편리성을 편리성 또는 사용자 편리성이란 개념 으로 설명하면서 사용자들이 서비스나 제품을 사용하거나 사 용하는 과정이 쉽고 사용하기가 편리하다고 느끼는 정도로 정 의하였다(Venkatesh \& Davis, 1996; Davis, 1989).

편리성은 온라인 사이트가 단순하고, 지각 가능하기 쉬운 것을 말한다. 정보의 접근 용이성과 거래과정의 단순성은 성공 적인 거래의 완성을 위해 중요하다. 온라인 사이트의 품질은 온라인 판매자에게 그것이 중심이 되는 사장과의 공유영역을 나타내기 때문에 특히 중요하다(Palmer \& Griffith, 1998).

\subsection{2. 보안성에 관한 연구}

보안성은 온라인 쇼핑몰을 사용할 때에 사용자들이 느끼는 결제 안정이나 개인정보 보호 등에 대해 느끼는 정도를 말한다.

Yoon(2010)은 온라인 은행 서비스에 관한 연구에서 보안성 을 중요한 변수로 설정하고 온라인 은행의 사이트 보안성이 이용자 만족도에 유의한 영향을 미친다고 하였다. Shen et al. (2010)은 이용자들이 온라인 은행을 이용할 때 큰 부담을 느 끼는 요인으로 보안성을 제시하였다. 보안성을 충족시킬 수 있 다면 고객의 온라인 은행시스템의 이용태도에 미치는 긍정적 인 영향을 실증하였다

\subsection{3. 상호작용성에 관한 연구}

상호작용성은 인간이 가상공간에서 느끼는 감각을 현실화 시키는 중요한 요인이다(Park \& Gretze, 2007).

온라인 여행사 사이트는 정보를 교류, 관광정보를 제공 또 는 사용자의 의견에 대해 신속하게 반영 및 응답, 문제점 해결 때문에 상호작용성은 관광에서 주요한 특성이라고 볼 수 있다 (Shang Guan et al., 2018).

Yoo and Stout(2001)의 연구에 의하면 소비자가 웹 사이트 와의 상호작용은 웹사이트에 대한 태도와 구매의도에 긍정적 인 영향을 미친다는 연구 결과가 나타났다. 


\subsection{4. 정보정확성에 관한 연구}

정보의 정확성에 관한 선행연구는 소비자가 온라인 쇼핑몰 사이트의 서비스 품질에 대해 인지도에 영향을 미칠 것이며 고객만족에 큰 영향을 미칠 것이다.

온라인 쇼핑몰이 잘못된 정보를 전달하여 고객의 기대 수준 에 만족하지 못하면 온라인 쇼핑몰에 대한 고객의 만족도가 감소된다(Dai \& Lee, 2018).

특히 온라인 여행관련 상품이나 서비스는 대부분 물리적인 실체가 없는 경험재이므로 소비자들은 정보에 대한 정확성에 대해 다른 온라인 상품보다 더욱 중요하게 생각할 것이라고 판단할 수 있으며, 따라서 정보정확성은 온라인 여행사 사이트 의 e-서비스품질을 구성하는 주요 요인으로도 도출하여 다른 변수들과의 영향관계를 파악해 볼 수 있을 것이다.

\subsection{5. 신뢰성에 관한 연구}

신뢰는 여러 분야에서 오랜 기간 많은 연구자들에 의해 연 구되어 온 개념이다(Bauer et al., 2002). 중요한 사람 간의 상 호작용으로 신뢰에 대해 기본적인 기대감을 이루어지게 되고, 과거의 중요한 사람에 대한 신뢰적인 행위는 개인적 신뢰경향 을 구축된다고 하였다(Tian et al., 2017).

신뢰는 경험의 축적을 통해 발전하기 때문에 개인의 신뢰수 준은 평가가 이루어지는 시점에서 각각 다르게 객관화 된다 (Lewicki \& Bunker, 1995). 인터넷상에서 정보원천에 대한 신 뢰성 관련 연구에서는 신뢰할 만한 정보원은 '신뢰 가능하고 (trustworthiness)', '전문성을 가진(expertise)' 것으로 표현된다 (Tseng \& Fogg, 1999). 이는 신뢰자(trustor)와 피신뢰자 (trustee)가 이전 지식이 없는 전자상거래와 같은 거래관계에서 는 양쪽 모두 초기 수준의 신뢰를 갖게 되고 신뢰를 중요하게 여기게 되며, 이 수준은 관계를 지속적으로 유지하면서 수정되 고 발전된다(Kim \& Prabhakar, 2000).

\subsection{6. 지각된 가치에 관한 연구}

지각된 가치(perceived value)란 사용자가 제품을 구매하거 나 서비스를 이용할 때 얻을 수 있는 모든 것으로 정의된다 (Zeithaml et al., 2000).

관광지의 호텔 레스토랑 이용 고객을 대상으로 지각된 가치 와 구매의도 간의 관계를 규명하였다. 연구 결과에 따라서 구 매의도를 결정하는데 긍정적인 영향을 미치는 주요 변수는 브 랜드 이미지, 품질, 화폐적 및 비화폐적 요소들이다. 특히 브 랜드 이미지는 고객들의 태도 형성에 결정적인 영향을 미치는 요인이며, 브랜드 이미지는 신뢰성, 평판, 친숙도 등을 통한 감정적 판단에 의해 형성된다고 하였다. 지각된 품질은 제품과 서비스의 성과에 영향을 미치고 있으며, 이는 다시 구매 의도 에 영향을 미치는 것으로 나타났다(Ann et al., 2010).

\subsection{7. 만족도에 관한 연구}

소비자 만족도는 기업이 제공하는 제품과 서비스가 고객들 의 기대를 만족시키는 정도를 측정하는 것이다.

Kim et al.(2009)은 만족도, 신뢰도 및 소매 품질의 측면에 충성도에 미치는 영향을 개념화한 충성도 개발 프로세스의 통 합 모델을 제안했다. 충성도는 만족도와 신뢰도에 영향을 받으 며, $\mathrm{e}$-신뢰도와 $\mathrm{e}$-만족도 간의 관계는 유의한 것으로 나타났다.
온라인 소매 품질 요인들은 만족도와 신뢰도에 서로 영향을 미쳤다.

\subsection{8. 재구매의도에 관한 연구}

재구매의도는 소비자가 이용한 서비스에 대해 다시 이용하 고 싶은 정도와 다른 사람에게 이 기업을 이용하도록 권유할 정도라고 하였으며, 고객이 미래에도 지속적으로 현재의 서비 스 공급자를 반복하여 이용할 가능성이라고 정의하였다 (Mcdougall, 2000).

기대와 불일치 그리고 만족과 태도 및 구매의도와 관계에 관한연구를 통해 소비자 만족이 구매 후 태도에 영향을 미치 며, 또한 재구매의도에도 영향을 미친다고 제시하였다(Oliver, 1981).

\section{3. 연구모형 및 가설설정}

\section{1. 연구모형}

본 연구의 모형은 이론적 배경에서 살펴본 온라인 여행사 사이트의 e-서비스품질이 재구매의도에 미치는 영향을 파악하 기 위해 선행연구를 검토하여 온라인 여행사 사이트의 e-서비 스품질(편리성, 보안성, 상호작용성, 정보정확성, 신뢰성), 지각 된 가치, 만족도, 재구매의도 간의 관계를 다음의 <Figure 1> 과 같이 제시하였다.

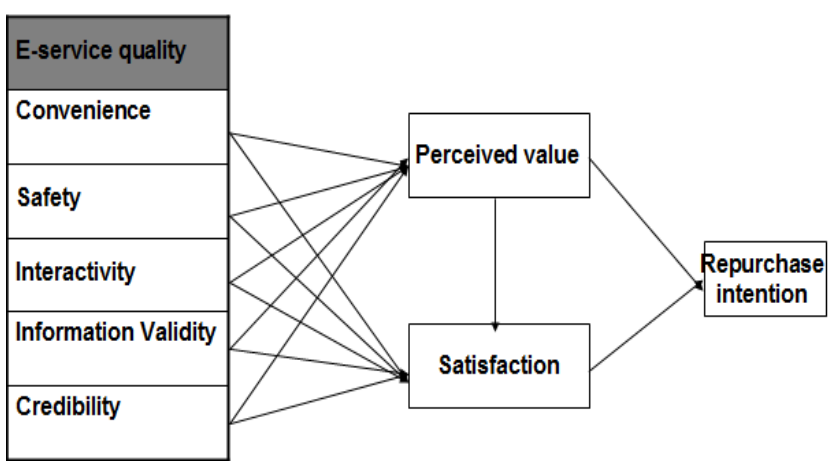

<Figure 1> Research model

\section{2. 연구가설의 설정}

Guo et al.(2018)은 택시 호출 앱 e-서비스품질과 고객 지각 된 가치가 지속사용의도에 미치는 영향에 관한 연구에서 택시 호출 앱의 e-서비스품질과 e-고객만족도와의 관계를 연구하였 다. 연구결과 항공사 서비스품질은 관광객의 만족도에 정의 영 향을 미치는 것으로 나타났다.

Jarvenpaa and Todd의 온라인 쇼핑몰의 서비스품질이 고 객의 쇼핑몰 만족에 미치는 영향에 대한 연구에서 편리성과 상품 정보의 정확성이 소비자의 쇼핑몰 만족에 긍정적인 영향 을 미치는 것으로 나타났다.

온라인 환경에서는 기업과 고객 간의 인적인 접촉이 없기 때문에 웹사이트의 e-서비스 품질과 관련된 거래 경험이 고객 
만족에 많은 영향을 미치게 된다(Szymanski \& Hise, 2000).

$<\mathrm{H} 1>$ : 온라인 여행사 사이트의 e-서비스품질은 지각된 가 치에 정(+)의 영향을 미칠 것이다.

$<\mathrm{H} 1-1>$ : 편리성은 지각된 가치에 정(+)의 영향을 미칠 것 이다.

$<\mathrm{H} 1-2>$ : 보안성은 지각된 가치에 정(+)의 영향을 미칠 것 이다.

$<\mathrm{H} 1-3>$ : 상호작용성은 지각된 가치에 정(+)의 영향을 미칠 것이다.

<H1-4>: 정보정확성은 지각된 가치에 정(+)의 영향을 미칠 것이다.

$<\mathrm{H} 1-5>$ : 신뢰성은 지각된 가치에 정(+)의 영향을 미칠 것 이다.

$<\mathrm{H} 2>$ : 온라인 여행사 사이트의 e-서비스품질은 만족도에 정(+)의 영향을 미칠 것이다.

$<\mathrm{H} 2-1>$ : 편리성은 만족도에 정(+)의 영향을 미칠 것이다. $<\mathrm{H} 2-2>$ : 보안성은 만족도에 정(+)의 영향을 미칠 것이다. $<\mathrm{H} 2-3>$ : 상호작용성은 만족도에 정(+)의 영향을 미칠 것이다. $<\mathrm{H} 2-4>$ : 정보정확성은 만족도에 정(+)의 영향을 미칠 것이다. $<\mathrm{H} 2-5>$ : 신뢰성은 만족도에 정(+)의 영향을 미칠 것이다.

지각된 가치는 많은 선행연구에서 소비자의 구매의도에 긍 정적인 영향을 미치는 것으로 인정되고 있다(Mcdougall, 2000).

Guo et al.(2018)은 택시 예약시스템의 품질요인이 고객만 족과 계속사용의도에 미치는 영향 연구에서 택시 예약시스템 의 정보, 서비스, 시스템 품질은 고객 만족에 미치는 영향을 분석하였는데 유의한 영향이 있음을 확인하였다.

만족도는 소비자가 상품을 재구매하고 지속적으로 사용하려 는 의도를 예측하는데 영향력이 강한 선행변수이고 소비자와의 장기적인관계를 형성하고 지키는 핵심 열쇠이다(Oliver, 1980).

$<\mathrm{H} 3>$ : 지각된 가치는 만족도에 정(+)의 영향을 미칠 것이다.

$<\mathrm{H} 4>$ : 지각된 가치는 재구매의도에 정(+)의 영향을 미칠 것이다.

$<\mathrm{H} 5>$ : 만족도는 재구매의도에 정(+)의 영향을 미칠 것이다.

\section{4. 실증분석}

본 연구에서 제시된 가설을 검증하기 위하여 온라인 여행사 사이트에 대한 이용 경험이 있는 중국 방한 관광객들을 대상으 로 설문조사를 실시하였다. 회수된 설문지 398부 중 불성실한 응답의 설문지 41 부를 제외한 357 부를 최종 분석에 사용하였다.
본 연구 설문응답자의 인구통계학적 특성을 살펴보면, 응답 자의 성별 비율은 남자가 181 명(50.7\%), 여자가 176 명(49.3\%) 으로 나타났으며, 연령은 20대 미만 114 명(31.9\%), 20대가 83 명(23.2\%), 30대가 87명(24.4\%), 40대가 38명(10.6\%), 50대 이상이 35 명 $(9.8 \%)$ 으로 20 대 미만의 응답자가 가장 많았다.

최종학력은 고등학교 이하 176 명(49.3\%), 대학재학 114 명 (31.9\%), 대학 졸업 43명(12.0\%), 대학원 이상 24명(6.7\%)으로 고등학교 이하가 가장 많이 참여한 것으로 확인되었다.

응답자들의 직업은 학생이 114 명(31.9\%), 회사원이 91명 (25.5\%), 자영업이 113 명(31.7\%), 공무원이 31명(8.7\%), 기타 가 8 명(2.2\%)으로 나타났으며 학생이 제일 많았다.

응답자의 온라인 여행사 사이트 이용 기간은 1 개월 미만이 47명(13.2\%), 1 6개월이 127명(35.6\%), 6개월 1년이 148명 (41.5\%), 1년 이상이 35명(9.8\%)으로 나타났으며, 응답자의 온 라인 여행사 사이트 이용회수는 1 3회가 133명(37.3\%), 4 6 회가 140명(39.2\%), 7 9회가 35명(9.8\%), 10회 이상이 49명 $(13.7 \%)$ 으로 나타났다. 한편 응답자가 이용한 온라인 여행사 사이트는 ctrip이 129명(36.1\%), qunar이 121명(33.9\%), tuniu 가 59명(16.5\%), Ivmama가 37명(10.4\%), 기타가 11 명(3.1\%) 으로 나타났다.

\section{1. 측정모형의 분석}

본 연구에서의 측정문항의 신뢰도는 0.798 이상으로 측정되 어서 확보되었다 . 표준 적재치(Loading)는 0.6이상으로 측정되 었고 수렴타당성이 확보되었다. Hair et al.(2006)이 제시한 적합 도가 $\mathrm{CMIN/DF}$ 값은 1-3 사이에, $\mathrm{RMR}$ 는 0.05 이하, $\mathrm{CFI}, \mathrm{RFI}$ $\mathrm{NFI}, \mathrm{IFI}, \mathrm{TLI}, \mathrm{AGFI} \mathrm{GFI}$ 은 0.8 이상이고 RMSEA은 0.05이하 수치의 수준에 의하면 본 모형은 적합도가 있음을 판단된다. 합 성신뢰도(CR, Composite Reliability)는 0.7 이상이면 구성개념의 신뢰성이 있고 집중타당도가 있음으로 판단되었으며 분산추출 지수(AVE, Average Variance Extracted)는 0.5이면 개념 신뢰도 혹은 수렴타당도가 확보되었다고 판단될 수 있다. <Table 2>와 같이 본 연구에서 추출된 8개 요인들의 $\mathrm{AVE}$ 값이 0.5 이상으로 그리고 $\mathrm{CR}$ 값이 모두 0.8 이상으로 나타났다. 따라서 본 연구에 서는 측정모형의 적합도가 확보되었음을 판단할 수 있다.

판별타당성(discriminant validity)은 두 잠재변수 간에 구한 $\mathrm{AVE}$ 값 각 잠재변수의 상관계수의 제곱, 즉 결정계수 $\left(r^{2}\right)$ 보다 크면 두 잠재변수 간에 판별타당도가 확보되었다고 평가할 수 있 다. 반대로 결정계수가 AVE값보다 큰 경우가 있으면 부분적인 판별타당도를 확보했다고 판단할 수 있다 <Table 3>에서 글씨체 가 굵게 표시된 대각선 부분의 요인의 AVE값이 나타나는데, 이 들이 다른 요인들과의 상관계수의 제곱 보다 모두 더 크므로 본 연구의 측정항목은 판별타당성을 가지고 있다고 볼 수 있다.

<Table 2> Quality criterion(CR, AVE, Cronbach's $\alpha$ ) and loadings

\begin{tabular}{|c|c|c|c|c|c|}
\hline Construct & Item & AVE & CR & Cronbach's $\alpha$ & Loading \\
\hline \multirow{4}{*}{ Convenience } & Convenience1 & \multirow{4}{*}{0.505} & \multirow{4}{*}{0.802} & \multirow{4}{*}{0.798} & 0.693 \\
\hline & Convenience2 & & & & 0.689 \\
\hline & Convenience3 & & & & 0.678 \\
\hline & Convenience4 & & & & 0.777 \\
\hline \multirow{4}{*}{ Safety } & Safety1 & \multirow{4}{*}{0.646} & \multirow{4}{*}{0.878} & \multirow{4}{*}{0.875} & 0.888 \\
\hline & Safety2 & & & & 0.854 \\
\hline & Safety3 & & & & 0.699 \\
\hline & Safety4 & & & & 0.758 \\
\hline
\end{tabular}




\begin{tabular}{|c|c|c|c|c|c|}
\hline Construct & Item & AVE & CR & Cronbach's $\alpha$ & Loading \\
\hline \multirow{4}{*}{ Interactivity } & Interactivity1 & \multirow{4}{*}{0.674} & \multirow{4}{*}{0.892} & \multirow{4}{*}{0.888} & 0.884 \\
\hline & Interactivity2 & & & & 0.825 \\
\hline & Interactivity3 & & & & 0.787 \\
\hline & Interactivity4 & & & & 0.783 \\
\hline \multirow{3}{*}{$\begin{array}{l}\text { Information validity } \\
\text { ( IV ) }\end{array}$} & IV1 & \multirow{3}{*}{0.573} & \multirow{3}{*}{0.801} & \multirow{3}{*}{0.801} & 0.764 \\
\hline & IV2 & & & & 0.739 \\
\hline & IV3 & & & & 0.767 \\
\hline \multirow{4}{*}{ Credibility } & Credibility1 & \multirow{4}{*}{0.620} & \multirow{4}{*}{0.867} & \multirow{4}{*}{0.866} & 0.818 \\
\hline & Credibility2 & & & & 0.770 \\
\hline & Credibility3 & & & & 0.748 \\
\hline & Credibility4 & & & & 0.811 \\
\hline \multirow{4}{*}{$\begin{array}{l}\text { Perceived value } \\
\text { ( PV ) }\end{array}$} & PV1 & \multirow{4}{*}{0.662} & \multirow{4}{*}{0.886} & \multirow{4}{*}{0.866} & 0.849 \\
\hline & PV2 & & & & 0.799 \\
\hline & PV3 & & & & 0.790 \\
\hline & PV4 & & & & 0.814 \\
\hline \multirow{4}{*}{ satisfaction } & satisfaction1 & \multirow{4}{*}{0.669} & \multirow{4}{*}{0.889} & \multirow{4}{*}{0.888} & 0.807 \\
\hline & satisfaction2 & & & & 0.765 \\
\hline & satisfaction3 & & & & 0.871 \\
\hline & satisfaction4 & & & & 0.824 \\
\hline \multirow{4}{*}{$\begin{array}{l}\text { repurchase } \\
\text { intention } \\
(\mathrm{RI})\end{array}$} & RI1 & \multirow{4}{*}{0.616} & \multirow{4}{*}{0.864} & \multirow{4}{*}{0.862} & 0.674 \\
\hline & $\mathrm{R} I 2$ & & & & 0.803 \\
\hline & RI3 & & & & 0.839 \\
\hline & $\mathrm{R} / 4$ & & & & 0.812 \\
\hline
\end{tabular}

$<$ Table 3> Correlations and AVE

\begin{tabular}{|c|c|c|c|c|c|c|c|c|}
\hline Construct & Con & Saf & Int & IV & Cre & PV & Sat & $\mathbf{R I}$ \\
\hline Convenience(Con) & 0.505 & & & & & & & \\
\hline Safety(Saf) & 0.626 & 0.646 & & & & & & \\
\hline Interactivity(Int) & 0.606 & 0.604 & 0.674 & & & & & \\
\hline Information validity ( IV ) & 0.539 & 0.589 & 0.595 & 0.573 & & & & \\
\hline Credibility(Cre) & 0.493 & 0.517 & 0.471 & 0.494 & 0.620 & & & \\
\hline Perceived value ( PV ) & 0.547 & 0.534 & 0.543 & 0.565 & 0.533 & 0.662 & & \\
\hline Satisfaction(Sat) & 0.633 & 0.648 & 0.534 & 0.618 & 0.601 & 0.627 & 0.669 & \\
\hline Repurchase Intention ( RI ) & 0.440 & 0.405 & 0.547 & 0.335 & 0.333 & 0.490 & 0.470 & 0.616 \\
\hline
\end{tabular}

\section{2. 가설검증}

본 연구의 가설 검정결과는 다음과 같이 제시하였다.

$<$ Table 4> Results of Hypothesis Analysis

\begin{tabular}{|l|c|c|c|c|c|}
\hline \multicolumn{1}{|c|}{ Route(Hypothesis) } & Estimate & S.E. & C.R. & p-value & Result \\
\hline H1-1: Convenience $\rightarrow$ Perceived value & 0.178 & 0.087 & 2.300 & 0.021 & Accepted \\
\hline H1-2: Safety $\rightarrow$ Perceived value & 0.097 & 0.080 & 1.312 & 0.190 & Rejected \\
\hline H1-3: Interactivity $\rightarrow$ Perceived value & 0.142 & 0.070 & 1.982 & 0.047 & Accepted \\
\hline H1-4: validity $\rightarrow$ Perceived value & 0.217 & 0.085 & 2.883 & 0.004 & Accepted \\
\hline H1-5: Credibility $\rightarrow$ Perceived value & 0.221 & 0.074 & 3.543 & ${ }^{* * *}$ & Accepted \\
\hline H2-1: Convenience $\rightarrow$ satisfaction & 0.168 & 0.070 & 2.447 & 0.014 & Accepted \\
\hline H2-2: Safety $\rightarrow$ satisfaction & 0.182 & 0.064 & 2.808 & 0.005 & Accepted \\
\hline
\end{tabular}




\begin{tabular}{|l|c|c|c|c|c|}
\hline \multicolumn{1}{|c|}{ Route(Hypothesis) } & Estimate & S.E. & C.R. & p-value & Result \\
\hline H2-3: Interactivity $\rightarrow$ satisfaction & 0.141 & 0.055 & 2.240 & 0.025 & Accepted \\
\hline H2-4: validity $\rightarrow$ satisfaction & 0.139 & 0.068 & 2.086 & 0.037 & Accepted \\
\hline H2-5: Credibility $\rightarrow$ satisfaction & 0.195 & 0.060 & 3.479 & ${ }^{* * *}$ & Accepted \\
\hline H3: Perceived value $\rightarrow$ satisfaction & 0.178 & 0.054 & 2.969 & 0.003 & Accepted \\
\hline H4: Perceived value $\rightarrow$ repurchase intention & 0.320 & 0.059 & 4.239 & ${ }^{* * *}$ & Accepted \\
\hline H5: satisfaction $\rightarrow$ repurchase intention & 0.274 & 0.064 & 3.690 & ${ }^{* * *}$ & Accepted \\
\hline
\end{tabular}

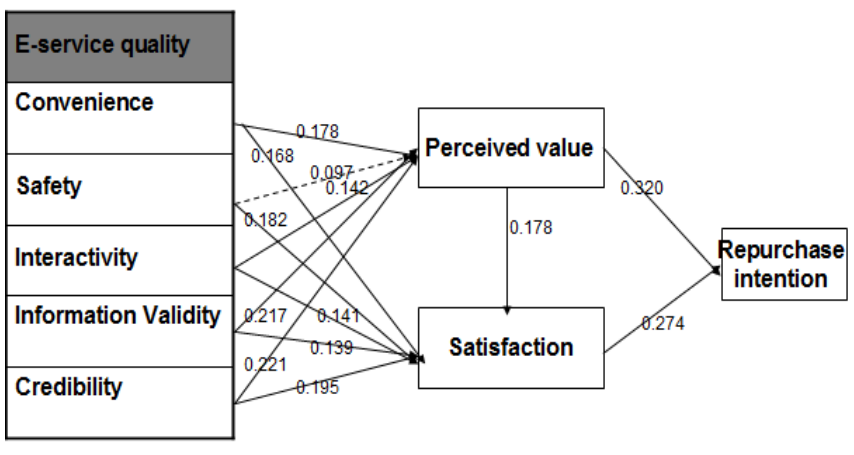

$<$ Figure 2> Structural model result

\section{5. 결론}

\section{1. 연구결과의 요약}

첫째, 온라인 여행사 사이트 e-서비스품질 중 편리성은 지 각된 가치와 만족도에 유의한 영향을 미치는 것으로 나타났다. 온라인 여행사 사이트의 이용자들은 여행 상품과 서비스에 대 한 정보가 알기 쉽게 제공되고, 사이트의 이용이 편하고 쉽다 고 생각할수록 지각된 가치와 만족도가 증가한다고 해석할 수 있다. 온라인 여행사를 포함한 대부분의 웹사이트 중 일부는 개발자 중심의 사이트 운영으로 사이트 이용자들을 불편하게 만들기도 한다. 지나친 팝업 광고나 다양한 사용자들의 접속환 경(웹브라우저의 종류, 화면해상도, 모바일 디바이스 등의 단 말장치)을 고려하지 않은 사이트 설계 및 운영은 지양해야 하 며, 특히 여행이라는 경험적 상품과 서비스 정보를 제공한다는 특성과 사이트를 통해 서비스 제공자와 사용자 간의 주고받는 정보의 양이 많다는 점은 더욱 사이트 편리성을 고려해야 한 다는 것을 의미한다.

둘째, 온라인 여행사 사이트 e-서비스품질 중 보안성은 지 각된 가치에 유의한 영향을 미치지 않는 것으로 나타났으며, 만족도에는 유의한 영향을 미치는 것으로 나타났다. 이는 온라 인 여행사 사이트의 이용자들이 제공하는 여행상품이나 서비 스의 소비와 구매를 위해 사이트에 제공하는 개인정보에 대한 유출 우려나 해킹, 구매과정 중 결제시스템의 경우 대부분의 사이트에서 보안을 기본으로 전제하고 있다고 인식으로 인해 이용자들의 경제적 - 심리적 편익과의 관계에는 영향을 미치지 않는 것으로 보이며, 만족도를 더욱 중요하게 생각하는 것으로 보인다.

셋째, 온라인 여행사 사이트 e-서비스품질 중 상호작용성은
지각된 가치와 만족도에 모두 긍정적 영향을 미치는 것으로 나타났다. 온라인 여행사 사이트에서 제공하는 상품이나 서비 스는 경험재라는 특성상 웹페이지를 통해 제공하는 정보에는 한계가 있어 사이트의 이용자와 관리자와의 상호작용을 통해 온라인 여행사 사이트 이용자의 지각된 가치와 만족도를 높일 수 있을 것이라고 볼 수 있다.

넷째, 온라인 여행사 사이트 e-서비스품질 중에 정보정확성 은 지각된 가치와 만족도에 모두 유의한 영향을 미치는 것으 로 나타났다. 온라인 여행사 사이트의 콘텐츠는 항공, 숙박, 식당, 쇼핑, 기타 예약서비스 등을 제공하는 많은 업체들과 연 동되어 운영하는 경우가 대부분이므로 다른 분야의 웹사이트 보다 정확한 정보를 제공하고, 유지하는 것이 더욱 중요하며, 지각된 가치와 만족도에도 영향을 미친다고 볼 수 있다.

다섯째, 온라인 여행사 사이트 e-서비스품질 중에 신뢰성은 지각된 가치와 만족도에 모두 중요한 영향을 미치는 것으로 나타났다. 온라인 여행사 사이트에서 제공하는 여행 상품이나 서비스는 시간이 한정적인 경우가 대부분이고, 서비스의 품질 에 불만이 있더라도, 상품이나 서비스를 소비한 이후에는 이를 취소하거나 환불을 받는 것이 거의 불가능하므로, 사이트 이용 자들은 신뢰성을 다른 e-서비스품질 요인보다도 가장 중요하 게 생각하는 것으로 볼 수 있다.

여섯째, 온라인 여행사 사이트의 지각된 가치는 만족도에 유의한 영향을 미치는 것으로 나타났다. 온라인 여행사 사이트 의 이용자들이 여행 상품이나 서비스 이용을 통해 얻은 경제 적·심리적인 긍정적 편익은 온라인 여행사 사이트에 대한 이 용자의 만족도를 증대시킬 것이라고 볼 수 있으며, 이는 온라 인 사이트 관련 다른 많은 연구들의 결과와도 일치한다.

일곱째, 온라인 여행사 사이트의 지각된 가치와 만족도는 재구매의도에 유의한 영향을 미치는 것으로 나타났다. 지각된 가치가 만족도보다 재구매의도에 미치는 영향이 큰 것으로 분 석되었으며, 이는 여행 상품이나 서비스가 같은 다양성, 구매 빈도, 가격적 차이 등에 기인하는 것으로 파악된다. 특히 상품 의 다양성과 가격적 차이에서 발생할 수 있는 많은 금전적 혜 택(가격 할인)을 경험한 이용자의 경우 재구매의도가 크게 증 가할 수 있을 것이다.

\section{2. 연구의 시사점}

본 연구를 통해 분석한 연구결과를 기반으로, 온라인 여행 사 사이트의 e-서비스품질을 중심으로 재구매의도를 높일 수 있는 전략적 시사점을 다음과 같이 제시할 수 있다.

첫째, 온라인 여행사 사이트의 e-서비스품질 요인 중 편리 성이 지각된 가치와 만족도에 영향을 미친다는 분석 결과를 토대로 온라인 여행사 사이트는 이용자들의 접속환경에 상관 없이 모든 접속 디바이스와 웹브라우저를 만족하는 웹표준 기 
술을 기반으로 하는 사이트 및 콘텐츠의 기획과 개발이 필요 하고, 모바일 사용자를 위해 하이브리드 앱을 통한 호환성 강 화를 위한 전략이 필요하다.

또한 여행 상품이나 서비스의 특성과 형태에 따른 구매와 예약에 필요한 해당 정보(비자, 여권, 결제 정보 등)를 편리하 게 전송하고 처리사항을 확인할 수 있는 시스템이 마련되어야 할 것이다. 최근 결제의 편리성을 위해 많은 사이트에서 도입 - 운영하고 있는 간편 결제 서비스도 필수라고 할 수 있다. 한 편 소비자들의 입장에서 여행 상품의 분류 기준을 마련하고, 상품을 편리하게 검색할 수 있는 서비스는 물론 지도서비스의 위치정보나 도시명, 관광 명소의 이름만을 입력하여 관련된 모 든 연계 상품이나 서비스(렌터카, 항공권, 기차표, 호텔, 숙소, 공연, 관광지 입장권 등)를 한 번에 볼 수 있는 서비스를 제공 하는 전략이 필요하다. 이는 한국 온라인 여행사가 중국 관광객 유치를 위한 기본적 운영 전략으로도 활용할 수 있을 것이다.

둘째, 온라인 여행사 사이트의 e-서비스품질 요인 중 보안 성이 만족도에 영향을 미치고, 지각된 가치에 영향을 미치지 않는다는 분석 결과를 토대로 온라인 여행사 사이트의 보안성 을 강화하고, 불편함을 최소화하는 전략이 필요하다. 보안성이 지각된 가치에 영향을 미치지는 않지만, 해킹 등의 사고 발생 시 다수의 이용자들에게 피해가 발생하고 여행사도 막대한 금 전적 손해가 발생할 수 있는 만큼 소홀히해서는 안된다. 여행 사에서 제공하는 상품이나 서비스 구매를 위해서는 다른 사이 트 이용과는 달리 매우 세부적인 개인정보가 전송되므로 이에 대한 관리 및 운영정책이 필수적일 것이다.

한편 소비자들의 입장에서는 보안성이 강화되면 필연적으로 사이트 이용에 불편함을 초래할 수밖에 없으므로 보안성을 강 화하고 사이트 이용의 불편함을 최소화할 수 있는 보안정책을 수립해야 한다. 앞서 설명한 간편 결제 서비스의 도입은 보안 성을 강화하고, 불편함을 최소화할 수 있는 서비스라고 할 수 있겠다.

셋째, 온라인 여행사 사이트의 e-서비스품질 요인 중 상호 작용성이 지각된 가치와 만족도에 영향을 미친다는 분석 결과 를 토대로 온라인 여행사 사이트는 이용자들과의 상호작용을 강화할 수 있는 전략이 필요하다. 특히 여행 상품이나 서비스 가 갖는 특성으로 인해 이용자들이 사이트에 제공되는 정보만 으로는 상품이나 서비스에 대한 충분한 이해가 어렵기 때문에 다양한 정보전달 매체를 활용하는 것이 필요하다. 상호작용을 통해 여행사 사이트 이용자들은 상품 및 서비스 정보를 획득 할 뿐만 아니라, 질문하고 대답하는 과정을 통해서 교감을 하 게 되고 이러한 교감은 여행사에 대한 지각된 가치와 만족으 로 이어질 수 있으며, 결국 재구매의도에도 영향을 미치게 될 것이다(Dai \& Lee, 2018).

따라서 온라인 여행사 사이트는 이용자과 상시로 상호작용 할 수 있는 서비스를 제공하거나 최근 대부분의 사용자들이 스마트폰 앱 형태로 이용하는 모바일 메신저를 활용하는 것도 좋은 전략이라고 판단된다. 중국 관광객을 대상으로 하는 온라 인 여행사 사이트 운영을 위해서는 중국 사람들이 주로 사용 하는 모바일 메신저인 QQ나 Wechat을 통해 상호작용 하는 등의 서비스를 제공하여 사이트 이용자의 문제를 신속하게 처 리할 수 있는 방안을 마련해야 할 것이다.

넷째, 온라인 여행사 사이트의 e-서비스품질 요인 중 정보 정확성이 지각된 가치와 만족도에 영향을 미친다는 분석 결과 를 토대로 온라인 여행사 사이트는 이용자들에게 정확한 정보 를 제공하기 위한 전략 마련이 필요하다. 여행사 사이트에서
제공하는 상품이나 서비스 정보는 일반적으로 항공, 숙박, 식 당, 쇼핑, 기타 예약서비스 등을 제공하는 많은 업체들과 연동 되어 운영하므로 해당 업체와의 협력을 통해 각각 서비스에 대한 API(application programming interface)를 연동하는 형태 로 서비스를 제공하는 것이 필수적이다. 이러한 사이트 운영 전략을 통해 여러 협력 업체에서 제공하는 정보를 공유하여 사이트 이용자들에게 제공함으로써 정보의 정확성을 담보할 수 있다.

또한 중국 관광객들을 대상으로 하는 온라인 여행사 사이트 는 상품이나 서비스 정보를 중국어로 정확하게 제공하기 위해 자동화된 번역시스템에 너무 의존하기보다는 이를 검수할 수 있는 제도와 서비스 방안을 마련하는 것이 필요하다.

다섯째, 온라인 여행사 사이트의 e-서비스품질 요인 중 신 뢰성이 지각된 가치와 만족도에 영향을 미친다는 분석 결과를 토대로 온라인 여행사 사이트는 이용자들의 신뢰성을 높이기 위한 전략 마련이 필요하다. 신뢰성은 온라인 여행사 사이트 이용자들이 가장 중요하게 생각하는 e-서비스품질 요인으로 신뢰성을 높일 수 있는 상품이나 서비스의 제공은 지각된 가 치와 만족에 매우 큰 영향을 미칠 수 있으며, 또한 사이트 이 용자들의 재구매에도 많은 영향을 미치기 때문에 전략적으로 가장 노력해야 할 부분이다.

많은 여행사 사이트들이 신뢰성을 높이기 위한 방안으로 다 른 이용자들의 여행 상품이나 서비스의 구매 또는 이용 후기 나 평가를 할 수 있는 서비스를 제공하고 있다. 그러나 이러한 서비스들은 이용자들이 자발적인 참여로 이루어졌다고 보기 어렵고, 최근에는 사이트 운영 기업에서 주도적으로 신뢰성을 높이기 위한 마케팅 수단으로 활용하고 있어 일부의 경우 실 제 이용자들이 체감하는 신뢰성 향상을 위한 전략으로 활용하 기에는 무리가 있다. 오히려 다른 이용자들의 상품이나 서비스 이용 경험을 신뢰성 향상을 위한 콘텐츠로 활용하기 위해서는 상품이나 서비스 정보 콘텐츠를 제공할 때 이용자들이 자발적 으로 참여하고, 공유한 $\mathrm{SNS}$ 를 활용하는 전략이 효과적일 것 이다. 이용자들이 여행 관련 상품이나 서비스에 대한 정보를 탐색할 경우 앞서 다른 이용자들이 경험한 상품이나 서비스에 대한 개인적이고, 주관적인 콘텐츠는 신뢰성 향상에 큰 영향을 미칠 것이며, 이는 곧 지각된 가치와 만족도에 영향을 미쳐 재 구매의도를 높일 것이다.

\section{3. 연구의 한계점 및 향후 연구방향}

본 연구에서는 관련 선행연구를 검토하여 온라인 여행사 사 이트 e-서비스품질이 지각된 가치, 만족도, 재구매의도에 미치 는 영향에 대한 분석하고자 하였으나, 다음과 같은 한계점을 갖고 있다.

첫째, 본 연구에서의 설문 문항은 선행연구를 바탕으로 본 연구에 맞게 수정하여 사용하였으나 온라인 여행사 사이트를 이용한 경험이 있는 방한 관광객들을 대상으로 방한의 구체적 인 목적이나 사이트 이용 목적의 구분 없이 조사하였다. 방문 목적이나 사이트 이용 목적에 따라 이용자들이 생각하는 e-서 비스품질의 세부 요인들과 지각된 가치, 만족도, 재구매의도에 미치는 영향에 차이가 있을 수 있는 만큼 향후 연구에서는 여 행사 사이트 이용자들의 방문 목적이나 사이트 이용 목적에 따른 세분화된 연구가 필요하다.

둘째, 본 연구에서는 온라인 여행사 e-서비스품질 요인으로 편리성, 보안성, 상호작용성, 정보정확성, 신뢰성의 5 가지의 변 
수를 도출하였으나, 지각된 가치, 만족도, 재구매의도에 영향 을 미치는 다른 요인을 포함하여 더욱 견고하고 설명력이 큰 연구모형의 설계와 분석 가능성이 있는 만큼 향후 연구에서는 좀 더 다양한 변수를 포함한 연구도 필요할 수 있다.

셋째, 중국 관광객은 방한 외국 관광객 중 가장 큰 비율을 차지하고 있어 방한 중국 관광객만을 본 연구의 대상으로 하였 으나, 다른 국가의 관광객을 포함하여 설문대상 표본의 확장을 통한 비교분석도 의미 있는 연구 주제가 될 수 있을 것이다.

\section{References}

Ann, G., Keum, L., \& Choi, Y. (2010). A study on the disaster preparedness of nurses in some Korean regional emergency medical centers. Journal of Military Nursing Research, 29(1), 94-109.

Bauer, H., Grether, M., \& Leach, M. (2002). Building customer relations over the internet, Industrial Marketing Management, 31, 155-163.

Carman, M. (1990). Consumer perceptions of service quality: An assessment of the SERVQUAL dimensions, Journal of Retailing, 66, 33-35.

Dai, W, Q., \& Lee, J, H. (2018). Effects of Website Characteristics and Delivery Service Quality on Repurchase Intention, International Journal of Industrial Distribution \& Business, 95),17-24.

Davis, D. (1989). Perceived usefulness, perceived ease of use, and user acceptance of information technology. MIS Quarterly, 13(3), 319-340.

Fassnacht, M., \& Koese, I. (2006). Quality of electronic services: Conceptualizing and testing a hierarchical model. Journal of Service Research, 9, 19-37.

Gronroos, C. (1984). A service quality model and its marketing implications, European Journal of Marketing, 18(4), 36-44.

Guo, Z, B., Park, U, Y., \& Lee, J, H. (2018). Effects of Taxi-Booking Apps of E-Service Quality on Use Intention in China, International Journal of Industrial Distribution \& Business, 9(4), 43-52.

Hair, J. F., Anderson, R. E., Tatham, R. L., \& Black, W. C. (2006). Multivariate Data Analysis with Readings(6th ed.). New Jersey: Prentice Hall.

Jarvenpaa, S. L., \& Todd, P. A. (1996). Consumer Reactions to Electronic Shopping on the World Wide Web. International Journal of Electronic Commerce, 1(2), 59-88.

Kim, K., \& Prabhakar, B. (2000). Initial trust, perceived risk, and the adoption of internet banking. ICIS 2000, 537-543.

Kim, Y., Jin, H., \& Swinneyb, H. (2009). The role of etail quality, e-satisfaction and e-trust in online loyalty development process. Journal of Marketing Management. 16(4), 239-246.

Lewicki, R., \& Bunker, B. (1995). Trust in relationships: A model of development and decline. Conflict, cooperation and justice: Essays inspired by the work of Morton Deutsch, 133-173.

Lewis, Q., \& Booms, H. (1983). The Marketing Aspects of Service Quality, in Berry, L. L., Shostack, G., \& Upah, G. (Eds.), Emerging Perspectives in Service Marketing. Chicago, IL: American Marketing Association.

Mcdougall, G, H. (2000). Customer Satisfaction with Service: Putting Perceived Value into the Equation. Journal of Services Marketing, 14(5), 392-410.

Oliver, R, L. (1980). A Cognitive Model of the Antecedents and Consequences of Satisfaction Decisions. Journal of Marketing Research, 172), 460-469.

Oliver, R, L. (1981). Measurement and Evaluation of Satisfaction Processes in Retail Settings. Journal of Retailing, 57, 25-48.

Palmer, J. W., \& Griffith, D. A. (1998). An emerging model of web site design for marketing. Communications of the ACM, 41(3), 44-51.

Parasuraman, A., Zeithaml, A., \& Berry, L. (1988). SERVQUAL: A multiple-item scale for measuring consumer perceptions of service quality. Journal of Retailing, 64(1), 12-40.

Park, A., \& Gretzel, U. (2007). Success factors for destination marketing web sites: A qualitative meta-analysis. Journal of Travel Research, 46(1), 46-63.

Santos, J. (2003). E-service quality: A model of virtual service dimensions. Managing Service Quality, 13(3), 233-247.

Shang Guan, J, L., Park, U, Y., \& Lee, J, H. (2018). A Study on the User's Sustainable Intention of Mobile Tourism: Focused on Chinese Tourists Visiting Korea. International Journal of Industrial Distribution \& Business, 9(5), 47-62.

Shen, C., Huang, Y., Chuand, H., \& Hsu, T. (2010). A benefit-cost perspective of the consumer adoption of the mobile banking system. Behaviour \& Information Technology, 295), 497-511.

Song, Y, T., \& Lee, J, H. (2018). The Present Situation and Development Methods of the Communication Industry in China. International Journal of Industrial Distribution \& Business, 9(4), 73-82.

Szymansky, D. M., \& Richard T. H. (2000). e-Satisfaction: An Initial Examination. Journal of Retailing, 76(3), 309-322.

Tian, X, F., Wu, R, Z., \& Lee, J, H. (2017). Use Intention of Chauffeured Car Services by $\mathrm{O} 2 \mathrm{O}$ and Sharing Economy. Journal of Distribution Science, 15(12), 73-84

Tseng, S., \& Fogg, J. (1999). Credibility and computing technology. Communications of the ACM, 42(5), 39-44.

Venkatesh, V., \& Davis, D. (1996). A model of the antecedents of perceived ease of use. Development and 
Test, Decision Sciences, 273), 451-481.

Yoo, C. Y., \& Stout, P. A. (2001). Factors Affecting Users' Interactivity with the Web Site and the Consequences of Users' Interactivity. In C. R. Taylor (ed.), Proceedings of the 2001 Conference of the American Academy of Advertising. American Academy of Advertising, 53-61
Yoon, C. (2010). Antecedents of customer satisfaction with online banking in China, The effects of experience. Computers in Human Behavior, 26, 1296-1304.

Zeithaml, A., Parasuraman, A., \& Malhotra, A. (2000). A conceptual framework for understanding e-service quality. Working paper, Marketing Science Institute, 54-170. 